\title{
ADVANCES IN APPLIED PROBABILITY \\ VOLUME 41 (2009): INDEX \\ Stochastic Geometry and Statistical Applications
}

ArmendáRIz, I., Cuevas, A. AND Fraiman, R. Nonparametric estimation of boundary measures

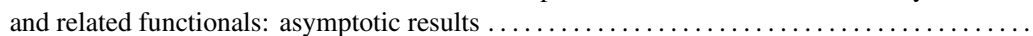

Balister, P., Bollobás, B., SARKar, A. And Walters, M. A critical constant for the $k$-nearest-

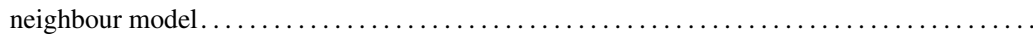

Bollobás, B. ANd Walters, M. Random transceiver networks . . . . . . . . . . . . . .

Baumstark, V. And Last, G. Gamma distributions for stationary Poisson flat processes .........

BŁaszczyszyn, B. AND Yogeshwaran, D. Directionally convex ordering of random measures, shot noise fields, and some applications to wireless communications . .

Bollobás, B. see Balister, P.

Calka, P., Michel, J. and Paroux, K. Refined convergence for the Boolean model............

Chan, H. P. Maxima of moving sums in a Poisson random field $\ldots \ldots \ldots \ldots \ldots \ldots \ldots \ldots \ldots \ldots$

Cowan, R. And Miles, R. E. Letter to the Editor: Convex hulls on a hemisphere .............

Cuevas, A. see Armendáriz, I.

DEREUDRE, D. The existence of quermass-interaction processes for nonlocally stable interaction and

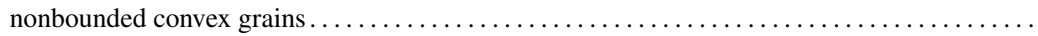

Fraiman, R. see ARMENDÁRIZ, I.

Harutyunyan, H. S. and Ohanyan, V. K. The chord length distribution function for regular

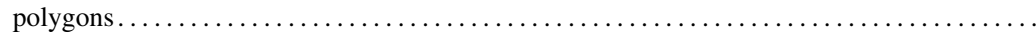

Huber, M. L. AND WolPERT, R. L. Likelihood-based inference for Matérn type-III repulsive point processes

KabluchKo, Z. AND Spodarev, E. Scan statistics of Lévy noises and marked empirical processes

LAST, G. see BAUMSTARK, V.

Michel, J. see CALKa, P.

Miles, R. E. see COWAN, R.

Ohanyan, V. K. see Harutyunyan, H. S.

Paroux, K. see CALKa, P.

Penrose, M. D. and Shcherbakov, V. Maximum likelihood estimation for cooperative sequential

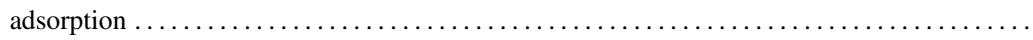

SARKAR, A. see BALISTER, P.

SchneIDER, R. Weighted faces of Poisson hyperplane tessellations $\ldots \ldots \ldots \ldots \ldots \ldots \ldots \ldots \ldots$

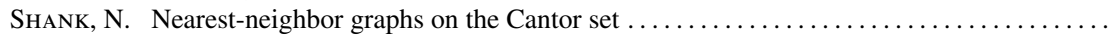

Shcherbakov, V. see Penrose, M. D.

Spodarev, E. see Kabluchko, Z.

Walters, M. see Balister, P.

Wolpert, R. L. see Huber, M. L.

YogeshWARAN, D. see BŁAszcZYSzYN, B. 